\title{
Polymeric Nanofibers Manufactured by Electrospinning of Styrene-Ethylene-Butylene-Styrene (SEBS) Composites ${ }^{+}$
}

\author{
Bogdan Spurcaciu 1, Lorena Iancu 1,2, , Mircea Filipescu 1, Rodica-Mariana Ion 1,2, Paul Ghioca 1, \\ Ramona Grigorescu ${ }^{1}$, Cristian Nicolae ${ }^{1}$, Raluca Gabor ${ }^{1}$, Maria Rapa ${ }^{3}$ and Ecaterina Matei ${ }^{3}$ \\ 1 The National Institute of Research and Development for Chemistry and Petrochemistry ICECHIM \\ Bucharest, 202 Spl. Independentei, 6th District, Bucharest 060021, Romania; \\ bogdansssss@hotmail.com (B.S.); mfilipescu3@gmail.com (M.F.); rodica_ion2000@yahoo.co.uk (R.-M.I.); \\ pghioca@yahoo.com (P.G.); rmgrigorescu@gmail.com (R.G.); ca_nicolae@yahoo.com (C.N.); \\ ralucagabor@yahoo.com (R.G.) \\ 2 Valahia University, Doctoral School of Materials Engineering Department, 13 Aleea Sinaia, \\ Targoviste 130004, Romania \\ 3 University POLITEHNICA of Bucharest, Center for Research and Eco-Metallurgical Expertise, \\ 313 Spl. Independentei, Bucharest 060042, Romania; rapa_m2002@yahoo.com (M.R.); \\ ecaterinamatei@yahoo.com (E.M.) \\ * Correspondence: lorena.iancu@icechim.ro \\ + Presented at the 15th International Symposium "Priorities of Chemistry for a Sustainable Development" \\ PRIOCHEM, Bucharest, Romania, 30th October-1st November 2019.
}

Published: 16 October 2019

Keywords: electrospinning; nanofibers; styrene-ethylene-butylene-styrene

The study aimed to synthesize nanofibers based on styrene-ethylene-butylene-styrene block-copolymers (SEBS) [1] and its composite derivatives, through the electrospinning (Figure 1) process [2]. Styrene-ethylene-butylene-styrene (SEBS) 1652 manufactured by Kraton was used as the basic polymer. This is a translucent thermoplastic elastomer, with a linear structure of triblock copolymer based on styrene and ethylene/butylene (SEBS), and with a Styrene/Rubber ratio of 30/70. Polymeric composites were synthesized in toluene solution, using SEBS and graphene at a gravimetric ratio of $80 / 20$ and $90 / 10$.

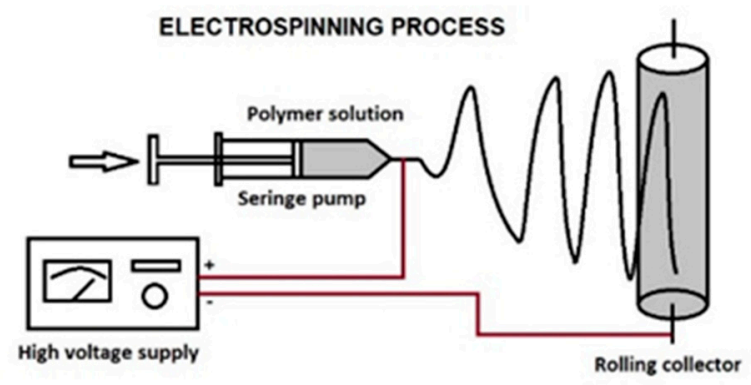

Figure 1. Electrospinning process scheme.

The composite materials based on SEBS and graphene, with a concentration of $20 \%$ polymer in toluene were used for the manufacture of nanofibers by electrospinning (Figure 2). 


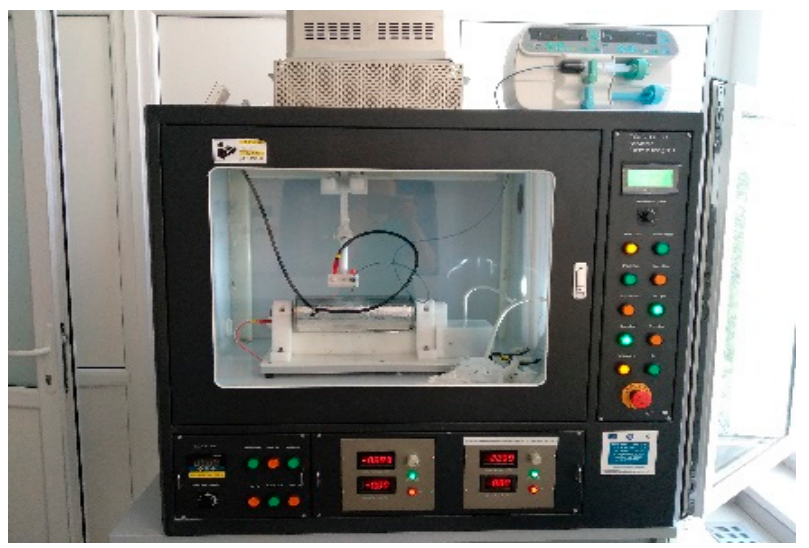

Figure 2. Electrospinnig equipment.

Nanofibers manufactured based on SEBS and SEBS with graphene composites were investigated by structural, thermal and chemical properties. The nanofibers based on SEBS and graphene obtained by electrospinning were characterized by ATR-FTIR analysis, Differential Scanning Calorimetry (DSC), Thermo-gravimetric Analysis (TGA) and Scanning Electron Microscopy (SEM). The results indicated an improvement of thermal and chemical properties of nanofibers composites based on SEBS and graphene, compared to SEBS 1652 elastomer.

Acknowledgments: This paper was supported by a Nucleu Program conducted with MCI support, project no. PN.19.23.03.01.04, contract no. 23N/2019.

\section{References}

1. Kurusu, R.S.; Demarquette, N.R. Blending and Morphology Control to Turn Hydrophobic SEBS Electrospun Mats Superhydrophilic. Langmuir 2015, 31, 5495-5503.

2. Ramakrishna, S.; Fujihara, K.; Teo, W.E.; Lim, T.C.; Ma, Z. An Introduction to Electrospinning and Nanofibers; World Scientific Publishing Company: Singapore, 2005.

() 2019 by the authors. Licensee MDPI, Basel, Switzerland. This article is an open access article distributed under the terms and conditions of the Creative Commons Attribution (CC BY) license (http://creativecommons.org/licenses/by/4.0/). 